Original Article

\title{
ADAPTATION OF DIABETES KNOWLEDGE QUESTIONNAIRE FOR SOUTH ASIAN COUNTRIES CONTEXT
}

\author{
KANCHANA NARSINGRAO DUSSA ${ }^{* 1}$, RAKESH KUMAR SAHAY ${ }^{2}$, PARIMALAKRISHNAN SUNDARARAJAN ${ }^{3}$, MENDU \\ VISHNUVARDHANARAO ${ }^{4}$
}

\begin{abstract}
1Research scholar, Department of Pharmacy, Annamalai University, Annamalai Nagar, Tamil Nadu, India, ${ }^{2}$ Prof. and Head of the Department,Department of Endocrinology, Hyderabad, Osmania General Hospital and Medical College, Telangana, India, Asst. Prof. Department of Pharmacy, Annamalai University, Annamalai Nagar, Tamil Nadu, India, ${ }^{4}$ Scientist F, Department of Biostatistics Hyderabad, National Institute of Nutrition, Telangana, India, Corresponding Author*: SRT-224, Jawahar Nagar, RTC-X road, Hyderabad, Telangana 500020
\end{abstract}

Email: kanchu2512@gmail.com

Received: 24 Aug 2017 Revised and Accepted: 02 Nov 2017

\begin{abstract}
Objective: To adapt diabetes knowledge questionnaire (DKQ) which would be suitable for assessing diabetes knowledge of subjects with type 1 or type 2 diabetes of the South Asian region.

Methods: For content validation of DKQ, Delphi survey of 111 opinion leaders was conducted during the South Asian Federation of Endocrine Societies (SAFES) summit in Hyderabad. The participants were endocrinologists, diabetologists, physicians, primary care physicians and researchers from India, Srilanka, Bangladesh, Nepal, and Pakistan. Participants were asked to indicate their opinion on each of the 15 questions of DKQ as whether to include it in modified DKQ on five points Likert's scale. Participants were also requested to provide their critical comments for modification, opinion, and applicability of DKQ. The consensus was considered to be reached when $67 \%$ of participants indicated agree or strongly agree, comments regarding modification, opinion, and applicability of DKQ. Data were analyzed using descriptive statistics with IBM SPSS 19.0 version.
\end{abstract}

Results: Final resultant modified DKQ comprises 18 multiple choice questions common in subjects with type- 1 or type-2 The questions assess the knowledge of subjects on diabetes management, sick day management, monitoring hypoglycemia and treatment.

Conclusion: Modified DKQ can be utilized for evaluating diabetes knowledge outcome of subjects with diabetes of the South Asian region. Rigorous re-validation of modified DKQ will be carried out.

Keywords: Measure, Outcome, Patient education, Pharmacist

(C) 2017 The Authors. Published by Innovare Academic Sciences Pvt Ltd. This is an open-access article under the CC BY license (http://creativecommons.org/licenses/by/4.0/) DOI: http://dx.doi.org/10.22159/ijpps.2017v9i12.22222

\section{INTRODUCTION}

Education of patients plays an important role in the effective management of diabetes. Formal assessment of diabetes knowledge of patients with diabetes is a prerequisite. Worldwide both the consumer and provider organizations are advocating for improving various methods and strategies for evaluation of the impact of diabetes education in subjects with diabetes [1-3]. However, such efforts for evaluation are hindered mainly because of lack of the formal agreement between the goals and targets [4-9] as well as there is a scarcity of standardized and validated assessment tools [10-12]. To overcome this difficulty, Diabetes Australia has established an Australian national consensus position for the outcomes and indicators to assess the impact of diabetes education in subjects with diabetes [13-14].

As per outcomes and indicators consensus, there are four patientfocused outcomes-knowledge and understanding, self-management, self-determination and psychological adjustment. Diabetes education interventions have the impact on all these four outcomes [13-15]. Eigenmann CA et al. [16] carried out a review to identify and evaluate instruments available for assessing these outcomes and whether these tools are capable and suitable to measure changes in these four main outcomes. Several questionnaires have been developed for assessing knowledge outcome. DKQ was developed in Australia and validated for assessing diabetes knowledge among subjects with diabetes [15]. DKQ [15] is suitable for assessing diabetes knowledge of subjects with type-1 or type-2 diabetes in daily practice, thus it was selected for validation in South Asian context. However, there are continuous changes in standards of diabetes care, guidelines for diabetes care and technologies utilized for diabetes care, thus DKQ requires modification for assuring content accuracy and revalidation is necessary if DKQ is modified [15].

Thus, in order to use DKQ [15] in countries like ours, it needs revision to assure content accuracy for variation in the South Asian region diabetes standards of care, guidelines of care, technologies and cultural context. Adaptation of DKQ [15] prior to utilization of the DKQ for the South Asian context is needed. Thus the objective of this present study was to adapt the diabetes knowledge questionnaire to make it applicable for use in the South Asian region for subjects with type 1 or 2 diabetes for assessing their knowledge outcome following diabetes education intervention.

\section{MATERIALS AND METHODS}

Methods

\section{Content validity}

Delegates of South Asian Federation of Endocrine Societies summit held on $17^{\text {th }}$ and $18^{\text {th }}$ August 2013, at Hyderabad were invited to participate in the first round Delphi survey [17]. The contents of original DKQ [15] were validated utilizing Delphi survey method [17]. The participants are international expert endocrinologists, diabetologists, physicians, primary care physicians and researchers from five countries: India, Srilanka, Bangladesh, Nepal, and Pakistan. To assess the content validity of the DKQ [15] all the delegates willing to participate were considered. Interested delegates were provided with a request for an appraisal letter to provide ideas about the survey. Data collection form was designed for this present study. 
Participants were requested to go through original DKQ [15] and mention their opinion on each of the 15 questions as to whether it should be included in the modified questionnaire on 5 points Likert's scale [18] (from strongly agree to strongly disagree), whether the question should be included if the phrasing was modified. Participants were also asked to provide their critical comments for changes in each of questions and answer options and their opinion and applicability of DKQ [15] in the South Asian context. The consensus was considered to be reached when at least $67 \%$ of participants indicated agree or strongly agree, comments regarding modification, opinion, and applicability of DKQ $[15,17]$. All responses were organized, coded, collated and analyzed using descriptive statistical methods with IBM SPSS 19.0 version.

The diabetes knowledge score assessment was set. Scores were calculated for modified DKQ. Points were given to all the right answer selections for each question. However, points were not given for wrong answers. Total scores need to be summed up to obtain diabetes knowledge scores of each subject with diabetes. For assessing their level of knowledge on diabetes these scores can be utilized. Maximum score attainable is 18 and the minimum score is 0 . Scores of $\geq 9$ considered as satisfactory and scores of $<9$ considered as unsatisfactory or poor knowledge scores. Greater score demonstrates better diabetes knowledge.

\section{RESULTS}

A first round Delphi survey [17] was conducted for assuring the content accuracy of DKQ [15], and for adaptation and modification of DKQ [15] items in the South Asian context. Of the 150 invited delegates, 111 delegates agreed to participate (74\%) in the first round Delphi survey [17]. 39 (26\%) did not participate. Reason for nonparticipation was due to lack of time. The participants' age range was from 24 to $76 \mathrm{y}$ with a mean age of $43.69 \mathrm{y}$. They were highly qualified with $48.1 \%$ post-graduation and $39.8 \%$ post-doctoral qualification (DM) and only $5.6 \%$ were graduates from the medical field. Their experience ranged from 0 to $50 \mathrm{y}$, with mean experience of $13.69 \mathrm{y}$. Participants practising in the urban location and rural locations are $94.4 \%$ and $4.6 \%$, respectively. Participants practising in private and government organization are $62.0 \%$ and $30.6 \%$, respectively. Demographic data of participants are presented in table 1.

Table 1: Demographics of participants of the delphi survey [17] analysis seta $(n=111)$

\begin{tabular}{|c|c|c|}
\hline Parameter & Mean & Percentage \\
\hline Age (y) & 43.69 & - \\
\hline Experience of participants (y) & 13.69 & - \\
\hline \multicolumn{3}{|l|}{ Level of education of participants } \\
\hline Post-graduation & - & 48.1 \\
\hline Postdoctoral qualification (DM) & - & 39.8 \\
\hline Graduates from the medical field & - & 5.6 \\
\hline Participants practicing in the urban location & - & 94.4 \\
\hline Participants practicing in the rural location & - & 4.6 \\
\hline Participants practicing in the private organization & - & 62.0 \\
\hline Participants practicing in the government organization & - & 30.6 \\
\hline
\end{tabular}

anclusion criteria: Participants who completed the study.

Table 2: The consensus was reached on the inclusion of following DKQ [15] questions and comments

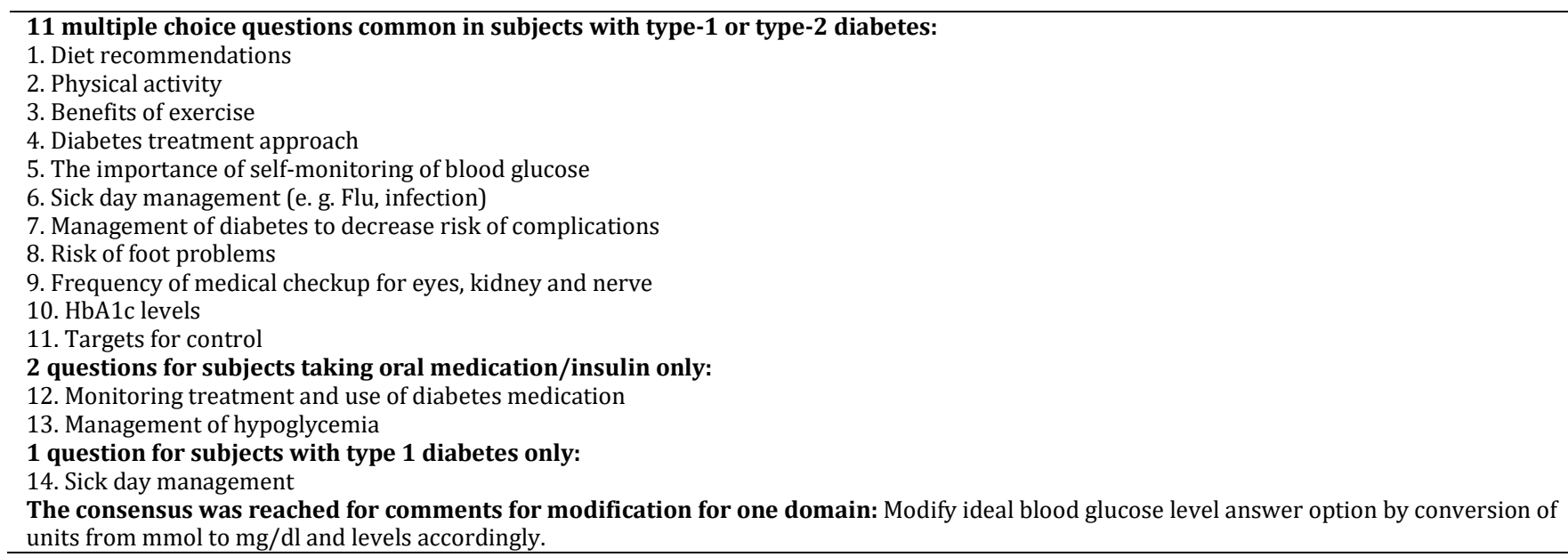

Table 3: The consensus was not reached on inclusion of following DKQ [15] questions and comments

\footnotetext{
The comment on the inclusion of 1 additional question:

1. The importance of adopting a healthier lifestyle.

The inclusion of 1 DKQ [15] question:

1. Diabetes service scheme. Participants (51\%) also provided the opinion to modify the diabetes service scheme to suit the South Asian context.

For modification of following comments:

- 15 questions and its options in diabetes knowledge questionnaire (except for conversion of units from $\mathrm{mmol}$ to $\mathrm{mg} / \mathrm{dl}$ ),

- Delete ethnic-specific term melanoma,

- Diet items and exercise should be relevant to South Asian context guidelines,

- Modify to simple terminology and language to suit the South Asian context literacy,

- Modify answer options for sick day management, hypoglycemia, foot problems and diabetes medication,

- Modify questions related to HbA1c, ideal blood glucose, diet, sick day management, and foot problem,

- Add more targets answer options for HbA1c.
} 
The consensus was reached on the inclusion of domains for HbA1c levels, exercise benefits, physical activity, diabetes management, eye, nerve and kidney examination, self-monitoring of blood glucose, hypoglycemia, sick day management, monitoring of treatment and targets for control except for the diabetes service scheme. The consensus was not reached on the comments for modification except for conversion of units from $\mathrm{mmol} / \mathrm{l}$ to $\mathrm{mg} / \mathrm{dl}$. The consensus was reached on the opinion and applicability of DKQ [15] but with some of the changes. Results of summarized comments from the first round Delphi survey [17] are illustrated in table 2 to table 4.

Table 4: Summary of comments for opinion and applicability of DKQ [15]

\begin{abstract}
$>\quad$ Participants also reached consensus on the usefulness and applicability of diabetes knowledge questionnaire, but it needs to be modified. Though it is important few comments ranged from $1 \%$ to $5 \%$ related to following:

$>$ The questionnaire is valuable, practical instrument and very useful for doctors, chiropodist, pharmacist, and nutritionist.

$>$ The questionnaire is useful for the doctor to plan management and helpful in conducting the surveys of the population at large in general practices, all (general) clinics, primary health care centers, outpatient departments. Assistance by pharmacist, diabetes educator and counsellor to doctors was considered as valid in this regard.

$>$ The questionnaire is useful for diabetics, pre-diabetics, patient, family, caretaker, attendant, and the public, society population of all age groups and of any gender.

$>$ The questionnaire needs translation and re-validation after modification for widespread use for the patient, caretaker, family, society, public education.
\end{abstract}

\section{Adaptation and modification of the DKQ}

Though consensus was not reached few respondents commented in this present study that original DKQ developed by CA Eigenmann et al. [15] is good to assess the level of awareness and knowledge of subjects regarding their disease, only for subjects with good educational status hence can be used for the limited group. And further respondents irrespective of their age, experience, geographic location commented that questionnaire needs to be simplified according to the South Asian subject's nutrition, lifestyle, literacy, knowledge, socioeconomic status in less technical terms. It should also include questions to make the patient and caretaker aware of our socioeconomic condition and cost-effectiveness of patient education and treatment. The questionnaire should be made more widely available as it is informative and explorative and includes patient for self-management (in their care) through patient education.

Based on constructive suggestions of respondents in the first round Delphi survey [17], a number of questions and answer options of original DKQ [15] were rephrased and modified so as to adapt simpler, short and appropriate language and terms and units for modified DKQ. Responses from the first round Delphi survey [17] were coded; analysis was carried out and collated into modified DKQ. Because of lack of time and complexity of the topic, we could not develop a more structured questionnaire with object-specific questions for the first round Delphi survey [17]. Researcher (KND) adapted and modified DKQ, based on domains answered as 'strongly agree and agree' by $\geq 67 \%$ participants and comments provided by $\geq$ $67 \%$ participants of the first round Delphi survey [17] and incorporated an appropriate alternative plan for certain a criterion where less than $67 \%$ consensus was noticed. However, 1 question on national diabetes service scheme was deleted as the consensus was not reached for the inclusion of this question. And 3 additional questions were incorporated in modified DKQ regarding lifestyle habits, and self-care required to be taken by subjects with diabetes in case of adverse drug reactions or drug-drug interactions and travelling. Endocrinologist (RS) approved the contents of modified DKQ. Final resultant modified DKQ comprises 18 questions on knowledge of diabetes, including its complications and required selfcare: 13 multiple choice questions common in subjects with type1/type-2 diabetes, 4 multiple choice questions for subjects taking oral medication and/or insulin only, and 1 multiple choice question for subjects with type 1 diabetes only. Out of 11 demographic questions, 7 demographic questions of original DKQ [15] were not modified and included in modified DKQ unchanged. Additional demographic questions on educational status, socioeconomic status, sources of medication and language most comfortable to speak, read and understand status are included in modified DKQ. Summary of domains of modified DKQ is presented in table 5 .

\title{
Table 5: Modified diabetes knowledge questionnaire comprises 18 questions on following domains
}

\author{
13 multiple choice questions common in subjects with type-1 and type-2 diabetes: \\ 1. Diet recommendations, \\ 2. Physical activity, \\ 3. Benefits of exercise, \\ 4. Lifestyle modification, \\ 5. Fasting blood glucose levels, \\ 6. Diabetes treatment approach, \\ 7. The importance of self-monitoring of blood glucose, \\ 8. Sick day management (e. g. flu, infection), \\ 9. Management of diabetes to decrease risk of complications, \\ 10. Risk of foot problems, \\ 11. Frequency of medical checkup for eyes, kidney and nerve, \\ 12. HbA1c levels, \\ 13. Targets for control. \\ 4 multiple choice questions for subjects taking oral medication and/or insulin only: \\ 14. Monitoring treatment and use of diabetes medication, \\ 15. Management of hypoglycemia, \\ 16. Precautions to be taken for travelling, \\ 17. Precautions to be taken for other reactions. \\ 1 multiple choice question for subjects with type 1 diabetes only: \\ 18. Sick day management.
}

\section{DISCUSSION}

The purpose of this study was to adapt DKQ [15] and make it applicable for use in the South Asian context for assessing diabetes knowledge as an outcome following diabetes education intervention. Acquiring knowledge may not lead to immediate change in behaviour; however, several studies discussed the necessity of assessing knowledge as an outcome of diabetes education 
intervention because it plays a prominent role in making informed health decision [19-23]. Adequate knowledge of the individual person with diabetes is considered to be a cornerstone to become competent in self-management and in turn prevent further health complications [24]. According to outcomes and indicators, consensus position identified that diabetes education has an impact on diabetes knowledge of subjects with diabetes and it is an outcome of diabetes education. Diabetes knowledge outcome assessment needs to be carried out with appropriate validated instruments [13-16].

Modified DKQ is simple to read and understand, unique with 18items knowledge questionnaire and seven additional demographic questions and one question each for educational status, socioeconomic status, and the sources of medication, the language most comfortable to speak, read and understand.

The study was conducted utilizing this resultant modified DKQ to assess the impact of diabetes education provided by the pharmacist along with an endocrinologist, in subjects with type 2 diabetes. However, the majority of subjects included in this study were illiterate or with the low level of education, thus modified DKQ was orally administered by conducting face to face interview of subjects with type 2 diabetes. Due to the shortage of resources, the interview could not be recorded [25-26]. An interim analysis was carried out to assess the diabetes knowledge among subjects with type 2 diabetes. Results indicated that diabetes knowledge of subjects with type 2 diabetes was poor. All the questions and answer options of modified DKQ can be easily understood and answered by educated as well as illiterate subjects with diabetes [25]. The study subjects were followed up longitudinally and the final analysis of the results indicated positive impact of diabetes education and counselling intervention on the humanistic outcome, i.e. diabetes knowledge of subjects with type 2 diabetes [26]. Renuga E. et al. conducted the study and assessed knowledge, attitudes, and practices as well as adherence to medication among patients suffering from diabetes. Impact of pharmacist-provided diabetes education on these parameters in these diabetic patients was also assessed. The author concluded that there was an improvement in knowledge, attitudes, and practices of these patients and in turn, it led to improvement in adherence to medication and clinical outcome. The author further concluded that impact of patient education needs to be assessed on a regular basis to achieve improvement in health outcomes [27].

\section{CONCLUSION}

Healthcare professionals can utilize this modified DKQ in clinics, outpatient departments, primary health care centres in a busy clinical setting in everyday practice as a research tool for planning, management, in evaluating the impact of diabetes education intervention in subjects with diabetes population of South Asian Countries. Modified DKQ can be utilized for conducting a survey of the population at large, pre-diabetics, patient, family, caretaker, attendant, and the public, society population of all age groups and of any gender in the South Asian Countries context. Diabetes educator, pharmacist, the counsellor can be valid persons to assist doctors in this regard.

\section{LIMITATION}

However, rigorous re-validation of the English version of modified DKQ will be carried out.

The text of the modified diabetes knowledge questionnaire and the scoring pattern has been shown in Appendices 1 and 2, respectively.

\section{SUPPLEMENT FILES}

Link 1:

https://innovareacademics.in/journals/index.php/ijpps/articl e/viewFile/22222/13462

\section{Link 2:}

https://innovareacademics.in/journals/index.php/ijpps/articl e/viewFile/22222/13463

\section{ACKNOWLEDGEMENT}

We would like to thank the delegates of South Asian Federation of Endocrine Societies summit participated in a Delphi expert panel survey for their valuable inputs. We would like to thank the organizers for giving the opportunity to conduct the survey in the South Asian Federation of Endocrine Societies summit.

\section{AUTHOR'S CONTRIBUTION}

Dr. Parimalakrishnan, Dr. Rakesh Sahay and Kanchana N. Dussa prepared a protocol. Kanchana N. Dussa (KND-Researcher) has conducted the survey under the supervision of Dr. Rakesh Sahay (RS-Endocrinologist). M. Vishnuvardhanarao has provided support for statistical analysis. Kanchana N. Dussa has modified DKQ and has written Manuscript under the guidance of Dr. Parimalakrishnan, Dr. Rakesh Sahay, and Dr. M. Vishnuvardhanarao.

\section{CONFLICT OF INTERESTS}

\section{Declared none}

\section{REFERENCES}

1. Corabian P, Harstall C. Patient diabetes education in the management of adult type 2 diabetes. Alberta: Alberta Heritage Foundation Med Res 2001:IHTA:23.

2. Peeples M, Mulcahy K, Tomky D, Weaver T. The conceptual framework of the national diabetes education outcomes system (NDEOS). Diabetes Educ 2001;27:547-62.

3. International Diabetes Federation. International Standards For Diabetes Education. 3rd edn Brussels: IDF; 2009.

4. Majumdar SR, Johnson JA, Bowker SL, Booth GL, Dolovich L, Ghali W, et al. A canadian consensus for the standardized evaluation of quality improvement interventions in type 2 . Diabetes Can J Diabetes 2005;29:220-9.

5. Sigurdardottir AK, Jonsdottir H, Benediktsson R. Outcomes of educational interventions in type 2 diabetes: WEKA datamining analysis. Patient Educ Couns 2007;67:21-31.

6. Colagiuri R, Girgis S, Eigenmann C, Gomez M, Griffiths R. National evidence-based guidelines for patient education in type 2 diabetes. Diabetes Australia NHMRC, Canberra; 2009. Available from: http://docplayer.net/7530199-Nationalevidence-based-guideline-for-patient-education-in-type-2diabetes.html. [Last accessed 04 Aug 2017]

7. Glasgow RE, Osteen VL. Evaluating diabetes education. Are we measuring the most important outcomes? Diabetes Care 1992;15:1423-32.

8. Home P, Coles J, Goldacre M, Manson A, Wikinson Ee. Health Outcome Indicators: Diabetes. Report of a working group to the Department of Health. National Centre for Health Outcomes, Oxford; 1999.

9. Naqib J. Patient education for effective diabetes selfmanagement: report, recommendations and examples of good practice. London: Diabetes UK; 2002.

10. Scientific Advisory Committee of the Medical Outcomes Trust. Assessing health status and quality-of-life instruments: attributes and review criteria. Qual Life Res 2002;11:193-205.

11. Ellis SE, Speroff T, Dittus RS, Brown A, Pichert JW, Elasy TA. Diabetes patient education: a meta-analysis and metaregression. Patient Educ Couns 2004;52:97-105.

12. Mokkink LB, Terwee CB, Knol DL, Stratford PW, Alonso J, Patrick DL, et al. Protocol of the COSMIN study: COnsensusbased standards for the selection of health measurement instruments. BMC Med Res Methodol 2006;6:2.

13. Eigenmann C, Colagiuri R. Outcomes, and indicators for diabetes education: a national consensus position. Canberra: Diabetes Australia; 2007.

14. Colagiuri R, Eigenmann C. A national consensus on outcomes and indicators for diabetes patient education. Diabet Med 2009;26:442-6.

15. Eigenmann CA, Skinner T, Colagiuri R. Development and validation of a diabetes knowledge questionnaire. Practical Diabetes Int 2011;28:166-70.

16. Eigenmann CA, Colagiuri R, Skinner TC, Trevena L. Are current psychometric tools suitable for measuring outcomes of diabetes education? Diabet Med 2009;26:425-36. 
17. Duffield C. The delphi technique. Aust J Adv Nurs 1988;6:41-5.

18. Likert RA. Technique for the measurement of Attitudes. Arch Psychol 1932;140:5-55.

19. Tomky DM, Weaver TW, Mulcahy K, Peeples MM. Diabetes education outcomes: what educators are doing. Diabetes Educ 2000;26:951-4

20. Koopman DJEM, van der Bijl JJ. The use of self-efficacy enhancing methods in diabetes education in the Netherlands. Sch Inq Nurs Pract 2001;15:249-57.

21. Mulcahy K, Maryniuk M, Peeples M, Peyrot M, Tomky D, Weaver T, et al. Diabetes self-management education core outcome measures. Diabetes Educ 2003;29:768-803.

22. Mensing C, Boucher C, Cypress C, Weinger K, Mulcahy K, Barta $\mathrm{P}$, et al. National standards for diabetes self-management education. Diabetes Care 2003;26(Suppl 1):S149-56.

23. Heisler M, Piette JD, Spencer M, Kieffer E, Vijan S. The relationship between knowledge of recent HbA1c values and diabetes care understanding and self-management. Diabetes Care 2005;28:816-22.
24. Persell SD, Keating NL, Landrum MB, Landon BE, Ayanain JZ, Borbas C, et al. Relationship of diabetes-specific knowledge to self-management activities, ambulatory preventive care, and metabolic outcomes. Prev Med 2004;39:746-52.

25. Kanchana Dussa, Parimalakrishnan S, Rakesh Sahay. Assessment of diabetes knowledge using diabetes knowledge questionnaire among people with type 2 diabetes mellitus. Asian J Pharm Clin Res 2015;8:254-6.

26. Kanchana Dussa, Parimalakrishnan S, Rakesh Sahay, M Vishnuvardhanrao. Impact of pharmaceutical care on economic, clinical and humanistic outcomes in patients with diabetes mellitus type II. Int J Chem Phys Sci 2017;10:29-38.

27. Renuga E, Ramakrishnan SR, Vanitha Rani N, Thennarasu P, Kannan G. Impact of continuous patient counselling of knowledge, attitudes, and practices and medication adherence of diabetic patients attending outpatient pharmacy services. Asian J Pharm Clin Res 2016;9:364-9. 